\title{
Analysis of the Impact of Technology on Culture in Indigenous Communities: Mentawai Islands, Indonesia
}

\author{
Zulfadrim \\ Graduate School of Policy Science, \\ Ritsumeikan University \\ Osaka, Japan \\ ps0335hh@ritsumei.ac.jp
}

\author{
Yusuke Toyoda \\ Graduate School of Policy Science, \\ Ritsumeikan University \\ Osaka, Japan
}

\author{
Hidehiko Kanegae \\ Graduate School of Policy Science, \\ Ritsumeikan University \\ Osaka, Japan
}

\begin{abstract}
The indigenous knowledge embedded in indigenous cultures faces serious challenges due to the development and spreading of technology into indigenous communities. This paper examines the impact of technology on native culture in indigenous communities. Using data gathered via interview and questionnaire carried out on the Mentawai islands, this study examines the impact of technology by identifying the variables found at the research site. In this paper, the ownership of technology refers to the use of television, radio, mobile phones, and vehicles and to how use of these tools represents the penetration of technology in indigenous communities. Meanwhile, elements of culture, such as language, beliefs, native tools, art, kinship, and economy, are used as dependent variables. The findings of this paper show that the penetration of technology in indigenous communities has an impact on native culture. Penetration of technology reduces the community's ability to practice their own culture, which represents a negative impact. However, technology can also improve and preserve culture, which represents a positive impact. The results show that some technologies have had a positive impact, whereas others have had a negative impact on culture. This research aims to contribute to determining the impact of technology on culture using quantitative methods.
\end{abstract}

\section{Keywords: indigenous communities, technology, culture}

\section{INTRODUCTION}

Globalization has transformed the lifestyles of people all over the world. Information and communication technology are key in globalization. However, the increasing penetration of such technology can also have a negative impact. The rapid development of information and communication technology is evident in the global use of the internet, not only in developed countries, but also in the developing world. Audiovisual technology such television and radio is also spreading rapidly. As Vanclay [1] argued, every development has an impact, whether positive or negative, and in some cases, developments can have both positive and negative impacts. The cost of development generally is not sufficiently taken into account by the authorities, mostly because the impact is sometimes not easily identifiable or measurable.

Information, communication, and transportation are important for those who live areas prone to natural disaster. Mobile phones, radios, and televisions are useful when disasters occur. However, such technologies often fail to help after such disasters in developing countries, particularly in Indonesia, where most public communication collapses after disasters. Many natural disasters, mainly in developing countries, have indicated that people who rely only on technology do not easily survive disasters [2]. Those who survive the disasters also rely on the indigenous knowledge embedded in their culture. Therefore, there is a need to study how to integrate modern technology and indigenous knowledge.

This paper aims to determine the impact of information, communication, and transportation technology on indigenous communities. This research also aims to determine which type of technology has the smallest impact on indigenous communities, and which has the most significant negative impact.

\section{LITERATURE REVIEW}

Little research has been conducted to determine how technology has an impact on the cultures of indigenous communities. Some literature on how information technology can help promote the culture of indigenous communities in Latin America and Caribbean have been key in defining which aspects of technology can be used to preserve indigenous culture under the paradigm of digital revolution [3]. However, a study conducted in Malaysia found that indigenous people interacted infrequently with information technology due to a lack of education, lack of basic infrastructure, and the high cost of equipment in their area [4]. Harper [5] argued that technology can cause change in three different ways. Firstly, technology can increase the quality of life of a community. Secondly, technology can change interaction patterns in a society. Finally, technology can cause new problems not yet encountered by a society.

Much literature has used impact assessments for project implementation purposes, particularly the social impact assessment (SIA). The Interorganizational Committee on Guidelines and Principles for social Impact Assessment [6] defines the "SIA as an effort to assess or estimate, in advance, the social consequences that are likely to follow from specific policy action, program, and new policies". Moreover, the social impact assessment measures changes in multiple dimensions of a community as a result of intervention. One of the main purposes of the social impact assessment is to anticipate the effects of changes on a community and to provide these communities with ways of anticipating social impacts and with the ability to develop and implement alternative interventions [7]. 
Cultural impact assessment, which falls under the category of social impact assessment, is often one of the most difficult methods to quantify. King [8] stated that the cultural impact assessment historic and archaeological resources, whereas much other research deals with only one or the other. These studies tend to ignore belief systems, lifestyles, and other elements of culture that should be included to assess the cultural impact. Moreover, Goyder [9] argued that one of the difficulties in analysing the impact technology is based on whether the definitions of many technologies have the same denominators. If there are no shared characteristics, the types of technology should be analysed separately. After analysing the characteristics of each type of technology, the researcher should consider whether its use is ethical [10].

However, social cultural impact assessments do not produce risk management decisions; rather, they present only information about decisions' consequences [11]. However, this information can be used to draw conclusions whose intervention has either a positive or negative impact on indigenous culture. In this paper, the researcher aims to analyse the behaviours that have a positive impact, and what might change those behaviours negatively using quantitative methods, though existing studies have largely used qualitative method s. Since quantitative methods offer descriptive data, the method may offer a precise interpretation of how independent variables have an impact on dependent variables. However, in many researchers interpretation, qualitative research must grasp the full meaning of the analysis. This study is expected to contribute to the discussion of technology's impact on culture, particularly in indigenous communities.

\section{RESEARCH METHODS}

The first step of this assessment is to identify variables relevant to the project that should be implemented. One of the most valuable resources, in terms of information, is knowledge of the indigenous community. Carley and Bustelo [12] stated that, in social and cultural impact assessments, the researcher should consider the full range of participatory techniques; by drawing on key informants, researchers can establish local knowledge. Community forums, for example, can function like focus discussion groups . This research is conducted in an indigenous community in Mentawai, West Sumatera, Indonesia. Mentawai is an archipelago situated in the western region of Sumatera and belongs to the West Sumatera Province, consisting of 323 islands and islets [13]. The four main islands are Siberut, Sipora, North Pagai, and South Pagai. Siberut has an area of 4,480 square kilometres, constituting the largest islands. $90 \%$ of the population in Siberut are indigenous Mentawai, while the other $10 \%$ are Minangkabau (a clan from West Sumatera), Javanese (indigenous to the island of Java), and Batak people (a clan from north Sumatera). This research aims to analyse the regression model, and a combination of qualitative and quantitative methods is used. A sample of 89 survey responses were collected from two villages in South Siberut Sub District, namely Muntei and Muaro. Muntei was chosen as representative of area with higher penetration of technology, while Muaro represents lower technology penetration. The research was conducted from August to September of 2018, the sample was chosen randomly based on household number rather than individual, meaning that one participant is one household.

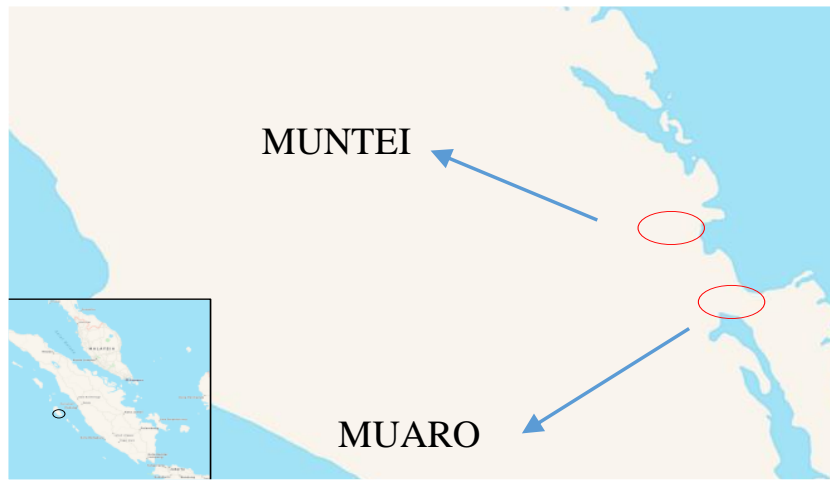

Figure 1 South Siberut sub district map and research area.

The World Summit on the Information Society (WSIS) stated that "in the evolution of information society, particular attention must be given to the special situation of indigenous community, as well as the preservation of their heritage and cultural legacy" [14]. Therefore, the evolution of information and communication technology in indigenous communities must not disregard indigenous technology and customs reflected in the community's culture. Culture itself has been defined in many ways by a number of scholars. Kluchohn [15] defined culture as patterned ways of thinking, feeling, and reacting. Meanwhile, Global Leadership and Organizational Behavior Effectiveness (GLOBE) defined culture as "shared motives, values, beliefs, identities and interpretations or meaning of significant events that result from common experience of member's collectives that are transmitted across generation" [16]. Based on Kluchohn's categorization, there are seven elements of culture, namely religious system, kinship, knowledge, economics, technology and tools, language, and arts.

In this paper's model, religious system is represented by community beliefs surrounding Sikerei (shaman) because Sikerei are believed to be a means of contacting God. In terms of kinship, this paper asked respondents if they still lived in Uma (traditional house for Mentawaians), which would often be occupied by a large number of relatives. The knowledge variable is defined as the communities' recognition of disaster risk and the ability to predict hazard, of which they were asked whether they knew how to predict incoming disasters and forecast weather. In defining economy, it is impossible to use income or expenditure as indicators in rural areas. Therefore, occupation was used as indicator. In technology and tools, the definition was based on communities' ability to interpret the meaning of Tuddukat, which is a traditional tool used to communicate with other clan members. The Tuddukat is a drum made from wood that is stuck to produce sound. In indigenous territories of the Siberut Island, each Uma should have a Tuddukat [17]. The language indicator used was defined as the ability to speak a native language. Finally, the arts indicator was defined in terms of knowledge of native symbols.

Another variable used in this research was population characteristics, as recommended by the Interorganizational Committee on Guidelines and Principles for Social Impact Assessment [3]. In the social impact assessment, population characteristics play a significant role in determining sociocultural factors. Some of the most important aspects of culture involve not only physical features, but also nonphysical features. That the reason to used population 
characteristic in this model. Ethnic group was also selected as independent variable and was used to examine whether other ethnic groups adapted elements of the native culture in their assimilation with local people. Specifically, this variable determined whether a participant was Mentawaian or not. This paper divided age into two categories, namely below 30 years old and above 30 years old, because technology started penetrating this area approximately 30 years ago. Education was also expected to have a significant influence on culture. In this paper's model, education level consisted of five categories based education level in Indonesia. Length of study defines the exact number of years of study compared to education level. Religion was defined in terms of the differing beliefs held by the members of each religious group. The number of individuals in households was also included in this model because it was expected to play a significant role in some elements of culture.

There is low technology penetration in Mentawai. The most common types of technology on Siberut island are television, radio, mobile phones, and vehicles. Therefore, in technology aspect represent by ownership sort of technology became the most important variables. Table 1 illustrates the ownership of television, radio mobile phones and vehicles across Muntei and Muaro. In Muntei, $64 \%$ of the population have television, while only $26 \%$ of the population of Muaro have television. $26 \%$ of respondents in Muntei have radios, whereas only $20 \%$ of the population of Muaro have radios. $87 \%$ of respondents in Muntei have mobile phones, whereas $40 \%$ of the population of Muaro have mobile phones. $74 \%$ of respondents in Muntei own vehicles, while only 36\% of respondents in Muaro own a vehicle. Based on these figures, Muntei has higher levels of technology penetration than Muaro.

Table 1 Technology penetration in Muntei and Muaro based on ownership of Television, Radio, Cellphone and Vehicle

\begin{tabular}{|l|l|l|l|l|l|l|l|l|l|}
\hline Area & \multirow{2}{*}{$N$} & \multicolumn{2}{|l|}{ TV } & \multicolumn{2}{l|}{ Radio } & \multicolumn{2}{l|}{ Phone } & \multicolumn{2}{l|}{ Vehicle } \\
\cline { 3 - 10 } & & $N$ & $\%$ & $N$ & $\%$ & $N$ & $\%$ & $N$ & $\%$ \\
\hline Muntei & 39 & 25 & 64 & 10 & 26 & 34 & 87 & 29 & 74 \\
\hline Muaro & 50 & 13 & 26 & 10 & 20 & 20 & 40 & 18 & 36 \\
\hline
\end{tabular}

Based on the seven community characteristics, the four aspects of technology, and the seven elements of culture, the proposed research model is presented Figure 2. This model is used to examine how technology may have impact on culture in indigenous communities. To develop the model, this paper used eleven combinations independent variable predictors:

- Location $\left(\mathrm{X}_{01}\right)$ consists of two areas in South Siberut: 0 for Muntei and 1 for Muaro

- Ethnic group $\left(\mathrm{X}_{02}\right)$ was dummied into two categories: $0=$ Mentawaian and $1=$ Other ethnic

- $\quad$ Age $\left(\mathrm{X}_{03}\right)$ was dummied into two categories: $0=>$ 30 years old and $1=<30$ years' old

- Education $\left(\mathrm{X}_{04}\right)$ was categorized into five levels: $0=$ no school, $1=$ elementary school, $2=$ junior high school, 3 = senior high school 4 = Diploma or Higher
- $\quad$ Length of Study $\left(\mathrm{X}_{05}\right)$ was measured using real data from respondents based on years of study

- Religion $\left(\mathrm{X}_{06}\right)$ was dummied into two categories: $0=$ Christian, 1 = other religion

- Number of individuals in household $\left(\mathrm{X}_{07}\right)$ was measured using data from respondents.

- Television ownership $\left(\mathrm{X}_{11}\right)$ was dummied into two categories: $0=$ No and $1=$ Yes

- Radio ownership $\left(\mathrm{X}_{12}\right)$ was dummied into two categories: $0=$ No and $1=$ Yes

- Mobile phone ownership $\left(\mathrm{X}_{13}\right)$ was dummied into two categories: $0=$ No and $1=$ Yes

- Vehicle ownership $\left(\mathrm{X}_{14}\right)$ was dummied into two categories: $0=$ No and $1=$ Yes

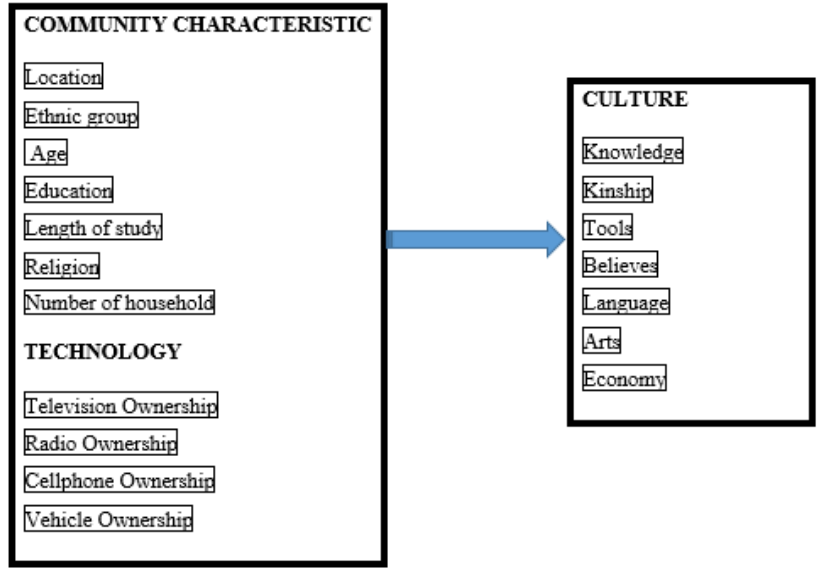

Figure 2 Research Model

The dependent variables (Y) consisted of seven elements of culture:

- Language $\left(\mathrm{Y}_{1}\right)$ measures the ability to speak Mentawaian and is comprised of 2 indicators: $0=$ Less Fluent and $1=$ Very Fluent

- Knowledge $\left(\mathrm{Y}_{2}\right)$ measures the knowledge of disaster risk in their area and is comprised of 2 indicators: 0 $=$ No knowledge and $1=$ Have Knowledge

- Kinship $\left(\mathrm{Y}_{3}\right)$ measures whether respondents still lived at home other family and is comprised of 2 indicators: $0=$ No and $1=$ Yes

- Tool $\left(\mathrm{Y}_{4}\right)$ measures ability to interpret the meaning of Tuddukat sound which comprises 2 indicators, 0 $=$ No and $1=$ Yes

- $\quad$ Economy $\left(\mathrm{Y}_{5}\right)$ determines occupation and consists of 6 indicators: $0=$ not working, $1=$ agriculture, $2=$ fisheries, 3 = services, $4=$ commerce, 5 = industry, 6 $=$ others

- $\quad$ Beliefs $\left(\mathrm{Y}_{6}\right)$ measures the beliefs in Sikerei (Shaman) and is comprised of 2 indicators: $0=$ No and $1=$ Yes

- Art $\left(\mathrm{Y}_{7}\right)$ measures ability to interpret traditional symbols and is comprised of 2 indicators: $0=$ No and $1=$ Yes 
A logistic regression was used to analyse the influence of independent variables on dependent variables. Logistic regression may also be referred to as the logistic model or logit model and analyses the relationship between multiple independent variables and a categorical dependent variable. This data is then used to estimate the probability of the occurrence of an event by fitting it to a logistic curve [18]. Although the logistic regression is the most popular multivariable method used in health science [19], the regression can also be used to make predictions in behavioural research [20], which is in line with this type of study.

There are two models of logistic regression. The first model, binary logistic regression, is used when the dependent variable is dichotomous (binary) and the independent variables or predictors are either continuous or categorical. The second model, multinomial regression, is used when the dependent variable is not dichotomous and consists of more than two categories. Both of these models use maximum likelihood estimation to evaluate the probability of categorical membership. These regression not assume normality, linearity, or homoscedasticity like other regression models. The equation of logistic regression is as follows:

$$
\operatorname{Logit}(y)=\ln (\text { odds })=\ln =a+\beta \chi(1) p 1-p
$$

where $\mathrm{p}$ is the probability of interested outcome, and $\mathrm{x}$ is the explanatory variable. The parameters of the logistic regression are $\alpha$ and $\beta$. This model is the simple logistic model. By extending the logic of the simple logistic regression to multiple predictors, one may construct a complex logistic regression as

$$
\operatorname{logit}(\mathrm{y})=\ln =\mathrm{a}+\beta 1 \chi 1+\ldots+\beta \mathrm{k} \chi \mathrm{k} .
$$

\section{A. Distribution of sample}

To further understand the characteristics of respondent on Siberut island, Table 2 illustrates the profile of respondents participating in the survey. $64 \%$ of the participant are male, and $36 \%$ are female. In terms of religion, $88 \%$ of participants are Christian, $10 \%$ are Muslim, and 2\% are Arat Sabalungan. In terms of ethnicity, $92 \%$ of participants are Mentawaian, while the remaining $8 \%$ are Minangnesse, Javanesse, and Batakness. In terms of education level, $56 \%$ respondents did not have education or did not pass elementary school with percentage, $13 \%$ graduated elementary school, $24 \%$ graduated junior high school, and $7 \%$ graduated senior high school or higher. In terms of location, $44 \%$ of respondents live in Muntei, and 56\% live in Muaro.

Table 2 Profile of respondents in Mentawai

\begin{tabular}{|l|l|c|c|}
\hline Category & Value & $N$ & $\%$ \\
\hline Gender & Male & 57 & 64,04 \\
\hline & Female & 32 & 35,96 \\
\hline Religion & Catholic & 75 & 84,27 \\
\hline & Islam & 9 & 10,11 \\
\hline & Christian & 3 & 3,37 \\
\hline & Arat Sabalungan & 2 & 2,25 \\
\hline Ethnic Group & Mentawaian & 82 & 92,13 \\
\hline & Minangnesse & 4 & 4,49 \\
\hline & Javanesse & 2 & 2,25 \\
\hline & Bataknesse & 1 & 1,12 \\
\hline Education level & No Pass the elementary & 50 & 56,18 \\
\hline & \multicolumn{2}{|c}{}
\end{tabular}

\begin{tabular}{|l|l|c|c|}
\hline & Elementary School & 12 & 13,48 \\
\hline & Junior High School & 21 & 23,60 \\
\hline & Senior High School & 2 & 2,25 \\
\hline & Diploma/higher & 4 & 4,49 \\
\hline Location & Muntei & 39 & 43,82 \\
\hline & Muaro & 50 & 56,18 \\
\hline
\end{tabular}

\section{B. The impact of technology on indigenous communities' culture}

In this analysis, binary logistic regression was used to examine the impact of independent variables on dependents variables. To resolve multicollinearity in binary logistic regression, simple binary logical regression is used to specify and inspect which predictors contribute to predicting the dependent variables and exclude those that do not. This process is conducted by made a simple logistic regression or bivariate regression for each predictor, wherein the predictors with significance of less than 0.250 are analysed in a multivariate regression. In this step, all candidates undergo binary logical regression. In this paper, a multinomial logistic regression was used to examine the impact of technology on economy.

\section{Predictions of technology and population variables on native knowledge}

In terms of native knowledge, binary logistic regression analyses show that the model proposed fit with the data (Nigelkerke R2 $=0.594$, sig $=0,000$ and $\square=-1.723$ ). The contribution of each predictor shows that location $(\square=2.670$ and $\mathrm{OR}=14.435, \mathrm{p}<0.050)$ and radio ownership $(\square=3.137$ and $\mathrm{OR}=23.035, \mathrm{p}<0.050)$ significantly predicted native knowledge of disaster risk in their area. For native language, the equation model can be formed as follows:

Ln $\mathrm{P} / 1-\mathrm{P}=-1.723+2.670$ location +3.137 Radio ownership +0.772 Mobile phone ownership +0.894 Vehicle ownership

Predicted $=(\operatorname{EXP}(-1.723+(2.670)+(3.137)+(0.772)+$ $(0.894))) /(1+\operatorname{EXP}(-1.723+(2.670)+(3.137)+(0.772)+$ $(0.894)))$

This finding predicts that people who live in Muntei are more likely to be aware disaster risk compared to those who live in Muaro. Moreover, those who own radios are more likely to know about disaster risk compared to those who do not own a radio.

\section{Predictions of technology and population variables on kinship}

The model of kinship also fit the data ((Nigelkerke R2 $=0.463$, sig $=0,000$, and $\square=1.104$ ). Two variables significantly contributed to this dependent variable, namely television ownership ( $\square=-2.312$, OR $=0.099$, and $\mathrm{p}<0.050$ ) and radio ownership ( $\square=2.454, \mathrm{OR}=11.638$, and $\mathrm{p}<0.050$ ) significantly predicted kinship in Mentawai communities. The equation for this variable is as follows: 
Ln $\mathrm{P} / 1-\mathrm{P}=1.104+(-1.275)$ location $+(-1.182)$ ethnic group +0.072 length of study $+(-2.312)$ television ownership +2.454 Radio ownership + (-0.559) Mobile phone ownership

Predicted $=(\operatorname{EXP}(1.104+(-1.275)+(-1.182)+(0.072)+$ $(-2.312)+(2.454)+(-0.559))) /(1+\operatorname{EXP}(1.104+(-1.275)+$ $(-1.182)+(0.072)+(-2.312)+(2.454)+(-0.559)))$

This finding shows that those who own a television less likely to live in Uma compared to those who do not have television. Furthermore, people who own a radio are more likely to live in Uma compared to those who do not own a radio.

\section{E. Predictions of technology and population} variables on tools and native technology

The model of tools and native technology fit the data (Nigelkerke R2 $=0.743$, sig $=0,000$, and $\square=0.112$ ). Four variables significantly contributed to this dependent variable, namely location $(\square=4.356$, OR $=77.934$, and $\mathrm{p}<0.050)$, age $(\square=2.583, \mathrm{OR}=13.328$, and $\mathrm{p}<0.050)$, television ownership ( $\square=-2.641$, OR $=0.071$, and $\mathrm{p}<0.050$ ), and mobile phone ownership ( $\square=-2.560$, OR $=0.077$, and $\mathrm{p}<0.050$ ). The equation for these variables is as follows:

Ln P/1-P $=0.112+4.356$ location $+(-2.299)$ ethnic group +2.583 Age $+(-0.076)$ length of study $+(-2.112)$ Religion + 1.004 Number of individuals in household $+(-2.641)$ television ownership $+(-2.560)$ Mobile phone ownership

Predicted $=(\operatorname{EXP}(0.112+(4.356)+(-2.299)+(2.583)+$ $(-0.076)+(-2.112)+(1.004)+(-2.641)+(-2.560))) /(1+\mathrm{EXP}$ $(0.112+(4.356)+(-2.299)+(2.583)+(-0.076)+(-2.112)+$ $(1.004)+(-2.641)+(-2.560)))$

This finding shows that people in Muntei are more likely to know the meaning of the Tuddukat compared to those who live in Muaro. People older than 30 are more likely to know the meaning of Tuddukat compared to those under 30 . Furthermore, those who own a television are less likely to not know the meaning of Tuddukat compare to those who do not have a television. Finally, those who own a mobile phone are less likely to not know the meaning of Tuddukat compare to those who do not own a mobile phone.

\section{F. Predictions of technology and population variables on belief systems}

In terms of the belief systems of the native people, the binary logistic regression analyses report in Table 2.2 shows that the model proposed fit the data (Nigelkerke R2 $=0.376$, $\operatorname{sig}=0,001$, and $\square=3.060$ ). The contribution of each predictor shows that only location $(\square=3.557$, OR $=35.061$, and $\mathrm{p}<$ $0.050)$ significantly predicted the belief systems of native people. In term of the belief system on Mentawai islands, the equation model can be formed as follows:

Ln P/1-P $=3.060+(3.557)$ location $+(-0.370)$ ethnic group $+(1.305)$ education $+(-0.479)$ length of study $+(-$ $0.884)$ television ownership $+(-1.138)$ vehicle ownership

Predicted $=(\operatorname{EXP}(3.557+(-0.370)+(1.305)+(-0.479)+$ $(-0.884)+(-1.138))) /(1+\operatorname{EXP}(3.557+(-0.370)+(1.305)+$ $(-0.479)+(-0.884)+(-1.138)))$
This finding suggests that people who live in Muntei are more likely to believe in Sikerei compared to those who live in Muaro.

\section{G. Predictions of technology and population variables on language}

In terms of language, the binary logistic regression analyses report in Table 2.2 shows that the model proposed fit the data (Nigelkerke R2 $=0.685$, sig $=0,000$, and $\square=7.278$ ). The contribution of each predictor shows that location $(\square=$ 3.996, OR $=0.018$, and $\mathrm{p}<0.050$ ) and television ownership ( $\square=3.928, \mathrm{OR}=0.009$, and $\mathrm{p}<0.050$ ) could significantly predict language. In terms of language, the equation model can be formed as follows:

Ln P/1-P $=7.278+(-3.996)$ location +0.458 Number of individuals in household $+(-3.928)$ television ownership $+(-$ $0.427)$ Mobile phone ownership

Predicted $=(\operatorname{EXP}(7.278+(-3.996)+(0.458)+(-3.928)+$ $(-0.427))) /(1+$ EXP7.278 + $(-3.996)+(0.458)+(-3.928)+(-$ $0.427)))$

This finding suggests that those who live in Muntei are less likely to speak Mentawai language fluently compared to those who live in Muaro. Furthermore, those who own a television are less likely to speak Mentawai language fluently than those who do not own a television.

\section{H. Predictions of technology and population variables on knowledge of local arts}

The model of knowledge of local arts fit the data (Nigelkerke R2 $=0.459$, sig $=0,000$, and $\square=4.836$ ). Two variables significantly contributed to this dependent variable, namely location $(\square=2.038$, OR $=7.677$, and $\mathrm{p}<0.050)$ and ethnic group $(\square=1.434$ and $\mathrm{OR}=4.194, \mathrm{p}<0.050)$. The equation for this variable is as follows:

Ln P/1-P $=4.836+2.038$ location +1.434 ethnic group + $(-3.633)$ religion $+(-0.415)$ television ownership $+(-1.086)$ vehicle ownership

Predicted $=(\operatorname{EXP}(4.836)+(2.038)+(1.434)+(-3.633)+$ $(-0.415)+(-1.086))) /(1+\operatorname{EXP}(4.836)+(2.038)+(1.434)+$ $(-3.633)+(-0.415)+(-1.086)))$

This finding implies that People in Muntei are more likely to know about local arts compared to those who live in Muaro, and Mentawaians are more likely to know about local arts compared to non-Mentawaians.

\section{Predictions of technology and population variables on economic aspects of the local community}

In this variable, a multinomial logistic regression was used to examine the impact of technology and population characteristics on economic aspects of the indigenous communities. Before conducting the multinomial logistic regression, every independent variable was examined using the crosstab method in descriptive statistics. All variables with $\mathrm{p}<0.50$ were considered candidates. All the candidate were used in the multinomial logistic regression.

Based on the results of the likelihood ratio test in Table 2.1, 6 of 8 variables have significant $p$ value, namely ethnic group, education, length of study, number individuals in household, radio ownership, and mobile phone ownership. 
These variables have an impact on the occupations of indigenous communities in Mentawai. However, in parameter estimates, there is no single variable with significant values when the reference occupation is agriculture. It may be concluded that there are several variables that influence economy, either partially or independently. However, when all significant variables are combined, no variable has a significant impact on economic variables, Table 3.5 shows the Nagelkerke R-square and that the variety of independent variables in this study can explain $92 \%$ of the variables. Therefore, $92 \%$ of the variables used in this model have an impact on the independent variables, particularly economic variables.

Table 3 Likelihood rasio test and pseudeo R-square

\begin{tabular}{|c|c|c|c|c|}
\hline \multirow[t]{2}{*}{ Effect } & \multirow[b]{2}{*}{$\begin{array}{l}\text { Model } \\
\text { Fitting } \\
\text { Criteria } \\
-2 \quad \text { Log } \\
\text { Likelihood } \\
\text { of Reduced } \\
\text { Model }\end{array}$} & \multicolumn{3}{|c|}{ Likelihood Ratio Tests } \\
\hline & & Chi-Square & df & Sig. \\
\hline Intercept & $87.285^{\mathrm{a}}$ & .000 & 0 & . \\
\hline X05 & $104.040^{\mathrm{b}}$ & 16.755 & 6 & .010 \\
\hline X07 & $103.995^{\mathrm{b}}$ & 16.711 & 6 & .010 \\
\hline X01 & $98.340^{\mathrm{b}}$ & 11.056 & 6 & .087 \\
\hline $\mathrm{X} 03$ & $122.360^{\mathrm{b}}$ & 35.075 & 6 & .000 \\
\hline X04 & $128.831^{\mathrm{b}}$ & 41.546 & 24 & .015 \\
\hline $\mathrm{X} 11$ & $94.540^{\mathrm{b}}$ & 7.255 & 6 & .298 \\
\hline $\mathrm{X} 12$ & $102.497^{\mathrm{b}}$ & 15.212 & 6 & .019 \\
\hline $\mathrm{X} 13$ & $116.510^{\mathrm{b}}$ & 29.225 & 6 & .000 \\
\hline $\mathrm{X} 14$ & $92.350^{\mathrm{b}}$ & 5.065 & 6 & .536 \\
\hline \multicolumn{5}{|c|}{ Pseudo R-Square } \\
\hline \multicolumn{2}{|c|}{ Cox and Snell } & .874 & & \\
\hline \multicolumn{2}{|c|}{ Nagelkerke } & .920 & & \\
\hline \multicolumn{2}{|c|}{ McFadden } & .693 & & \\
\hline
\end{tabular}

\section{RESULTS}

Result s of the analysis imply that, in terms of location, people in Muntei are more likely to preserve their culture despite having higher levels of technology penetration than Muaro. This finding may be because Muntei collaborates with foreign NGO in promoting local culture through Yayasan Pendidikan Budaya Anak Mentawai (Mentawai culture education centre), which aims to promote local culture. Muaro has not worked with this NGO. This reason also explains why people in Muntei know about disaster risk in their area compare to those who live in Muaro. Another possible explanation because Muntei experienced tsunami in 2010, whereas Muaro did not. In Muntei, Uma and Tuddukat are more common than in Muaro village, which may explain why people in Muntei are more likely to know the meaning of Tuddukat compared to those who live in Muaro.
In terms of beliefs, people in Muntei are more likely to believe in Sikerei compared to those who live in Muaro. One possible explanation for this difference is that people in Muntei refer to Sikerei when encountering problems related to health, whereas people in Muaro already use modern medical institutions such as Puskesmas (health centres). In Muaro, two Puskesmas have been built by the government, whereas Muntei only has one Puskesmas. However, in terms of language, those in Muntei are less likely to speak their native language fluently compared to those who live in Muaro. This result may be argued as an outlier, because other elements of culture have positive values. Muntei has been more deeply penetrated by technology than Muaro, as seen in Table 1.1. This finding is in line with human behavioural theory [21], which has argued that human behaviour is influenced by social pressures. Moreover, in terms of knowledge of traditional symbols, people in Muntei are more likely to be knowledgeable than people in Muaro, which may be because there are more cultural centres in Muntei compared to other areas of the region.

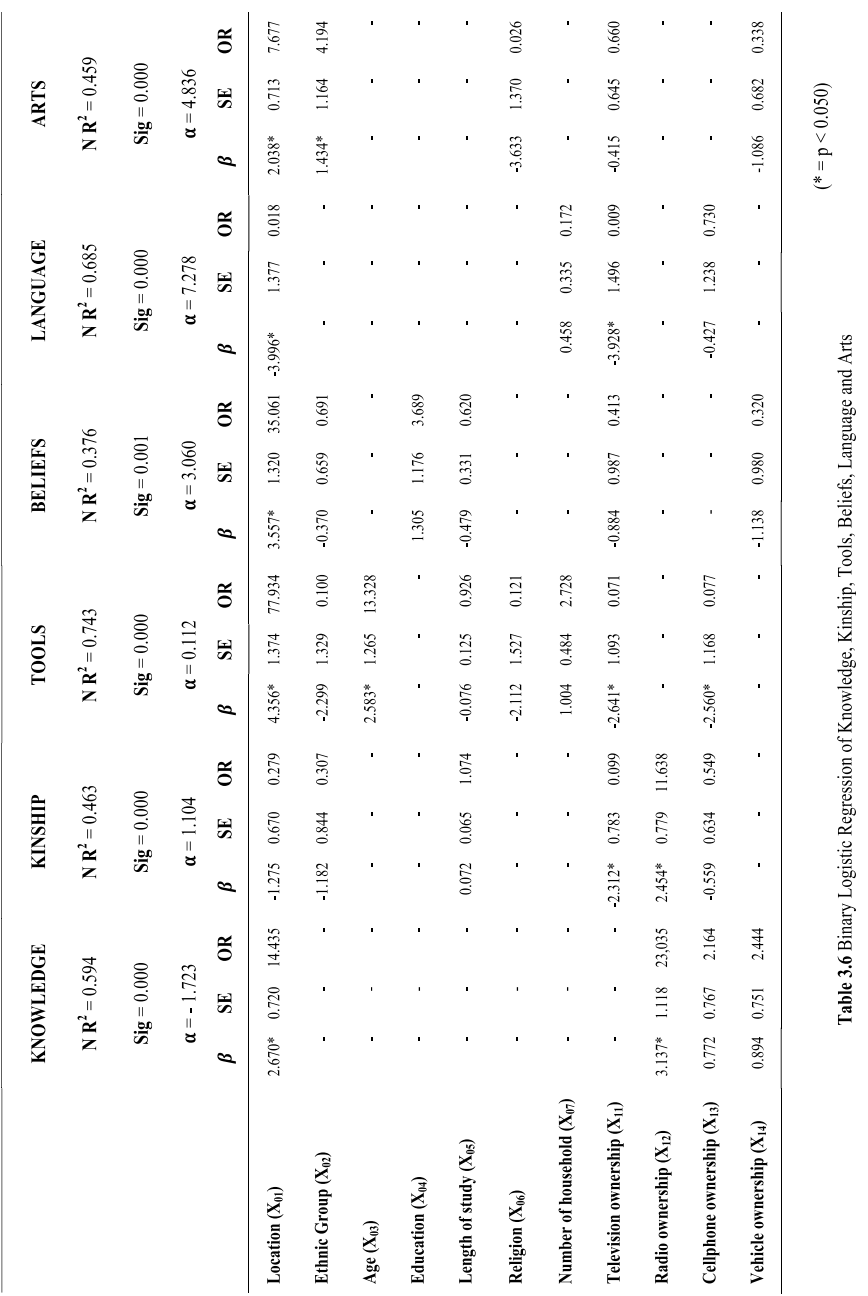

In the results model for ethnic groups, significant values can only can be found in art predictors, which suggests that ethnic groups do not correlation with other elements of culture, except for knowledge of traditional symbols. In terms of age, variable, only knowledge of the Tuddukat has significant value. This finding implies that more people over 30 years old know the meaning of Tuddukat sound compare to those below 30 years old. This finding may be because 
technology began to be introduced in Siberut approximately thirty years ago. In terms of education, length of study, religion, and number of individuals in household, there is no significant value, which means that this variable has no influence on the cultures of the indigenous communities. Although these variables have significance individually, they are of no significance in the final model.

Television ownership has a negative significant value compared to radio and mobile phone ownership, whereas vehicle ownership does not have a significant value. Television ownership has a negative significant value perhaps because indigenous people in Mentawai tend to live with their relatives . Most people who own televisions have their own house and live separately from their relative. For this reason, television ownership has an impact on kinship and the way that community members interact with their relatives. In term of villagers' ability to interpret the meaning of the Tuddukat, those who have televisions are less likely to know compared to those who do not have televisions. The possible explanation for this result is that people who have televisions tend to ignore the sound of the Tuddukat while watching television. Furthermore, television ownership also has a negative significant value in terms of Mentawaian fluency. There is no local television broadcast in Mentawai, and so those who own televisions are more likely to be exposed to Indonesian and English, meaning that they are not able to speak Mentawaian fluently as others.

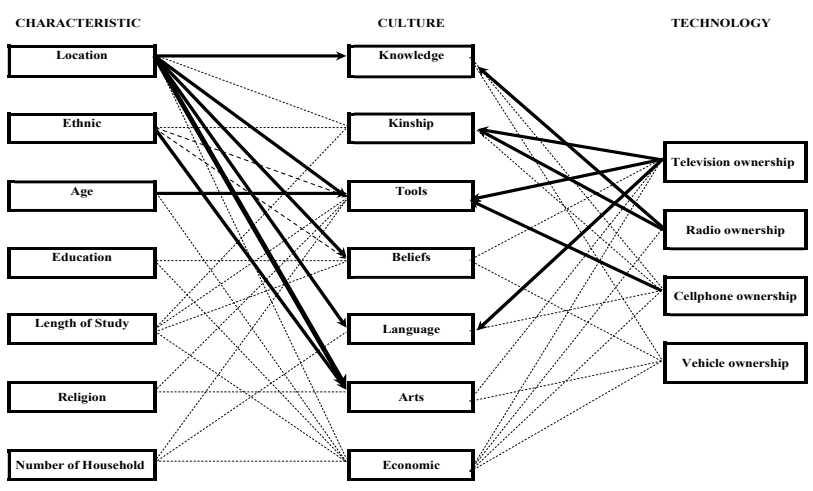

Notes: Bold lines indicate significant value, and dotted lines indicate insignificant paths

\section{Figure 3 Diagram of result analysis}

Radio ownership, based on its positive significant value, has a positive impact on culture. In terms of knowledge, radio offers knowledge of disaster risks in an area, and radio ownership has a positive significant value because the radio programmes are broadcasted in Mentawaian. Therefore, the information shared through radio broadcasts is easily understood by native communities. Meanwhile, in terms of kinship, radio owners are more likely to live with their relatives in the same house than those who do not own radios. This finding implies that radio owners are more closely related to their relatives. One possible reason for this closeness is that radio is one of the main sources of information for Mentawaian communities, which means that they often gather together while listening to the radio. Moreover, mobile phone ownership only has a significant impact on one variable, namely tools, specifically that people with mobile phones are less likely to understand the meaning of Tuddukat sound. A possible explanation for this phenomenon is that mobile phone owners tend to ignore the sound of Tuddukat because they believe that they can acquire greater information using their mobile phone, though they have realised that mobile phones can only be used in some locations. Finally, vehicle ownership, based on its insignificant value in the final model, has no significant impact on culture.

\section{CONCLUSIONS}

Mentawai, as an Indonesian indigenous community, has recently seen changes due to the introduction of technology. Although research on the impact of technology on culture is abundant, few studies have used quantitative methods. The quantitative method provides descriptive numerical data, which should be reinforced with qualitative research. In this research, the sample was taken from two different areas in South Siberut district, both of which had different characteristics in terms of technology penetration. The aim of this study was to compare between areas with lower and higher technology penetration. The independent variables used in this research were population characteristics, which were represented by area, ethnicity, age, education, length of study, religion, and number of persons in household. The independent variables in technology were television, radio, mobile phone, and vehicle ownership. The dependent variables used were elements of culture, such as knowledge beliefs, tools, arts, language, kinship, and economy.

The logical regression model predicted that almost all of the dependent variables, except for economy, would not be significantly affected by technology use. A closer look at the contribution of each predictor variable indicated that not all of the variables had an impact on culture. The analysis showed that some technology had a positive impact, other types of technology had a negative impact, and the remaining types of technology had no significant impact on culture at all. Specifically, vehicle ownership did not have a significant impact on culture.

This research has a number of limitations, as it had few examples to draw upon. This quantitative research is not common, even among anthropologists and social sciences scholars. Qualitative approaches are generally preferred because they can offer a more comprehensive understanding through observations and interviews compared to quantitative methods. This paper combines quantitative and qualitative methods, and qualitative methods are used in discussing the results of the quantitative methods and findings. Further research is required to explore further how this type of study may contribute to the social sciences.

\section{REFERENCES}

[1] Vanclay F 2003 Conceptual and methodological advances in social impact assessment. In H. A. Becker and F. Vanclay (Eds.), The international handbook of social impact conceptual and methodological advances (pp. 1-9). Cheltenham: Edward Elgar.

[2] Zulfadrim Z, Yusuke $\mathrm{T}$ and Kanegae H 2017 Recognizing and integrating indigenous knowledge into disaster early warning system in Mentawai. Internet Journal of Society for Social Management Systems, 1(11).

[3] Hernandez I and Cacagno S 2003 Indigenous peoples and the information society in Latin America and the Caribbean: A framework for action. Santiago, Chile: CEPAL. 
[4] Forte M 2002 "We are not extinct": The revival of Carib and Taino identities, the internet, and the transformation of offline Indigenous into online N-digenes. In Sicronía: An Electronic Journal of Cultural Studies.

[5] Delgado G 2003 Solidarity in cyberspace: Indigenous peoples online: Have a new electronic technologies fulfilled the promise they once seemed to hold for indigenous peoples? The answers are yes, and no. In NACLA, Report on the Americas, 35(5). 49-53.

[6] Ooi P H Y 2007 ICT and the Orang Asli in Malaysia. In L. E. Dyson, M. Hendicks, \& S. Grant (Eds.), Information technology and indigenous people (pp. 55-57). London, UK: Publisher .

[7] Harper C L 1989 Exploring social change. New Jersey: Prentice Hall.

[8] Interorganizational Committee on Guidelines and Principles for Social Impact Assessment. 1995 Guidelines and principles for social impact assessment. Environment Impact Assessment Review, 15, 11-43.

[9] Burdge R J and Robertson R A 1998 Social impact assessment and the public involvement process. In R. J. Burdge (Ed.), A conceptual approach to social impact assessment (Revised ed., pp. 183-192). Middleton, WI: Social Ecology Press.

[10] Western, J and Lynch, M 2000 Overview of the SIA process. In L. R. Goldman (Ed.), Social impact analysis: An applied anthropology manual (pp. 35-62). New York, NY: Berg.

[11] King T F1998 How the archeologists stole culture: A gap in American environmental impact assessment practice and how to fill it. Environmental Impact Assessment Review, 18, 117-133.

[12] Goyder J 1997 Technology and society: A Canadian perspective. Peterborough, England: Broadview Press. isE़

[13] Fink S 2007 Ethics vs. innovation? The impact of embryo research laws on the innovative ability of national economies. Science, Technology and Innovation Studies, 3,2 .

[14] Stahl R, Bachman R, Barton A, Clark J, deFur P, Ells S, Pittinger C, Slimak M and Wentsel R 2001 Risk management: Ecological risk-based decision-making. Pensacola, FL: Society for Environmental Toxicology and Chemistry.

[15] Carley M J and Bustelo E S 1984 Social impact assessment and monitoring: A guide to the literature. Boulder, CO: Westview Press.

[16] Bappeda Kabupaten Kepulauan Mentawai. 2004 Profil Kepulauan Mentawai. Tuapeijat .

[17] Due to the awareness raising effort of indigenous representative at the wsis proceeding the Geneva Declaration and the Tunis Commitment. 2003

[18] Kluckhohn C 1954. Culture and behavior. In G. Lindzey (Ed.), Handbook of social psychology (Vol. 2). City, Country : Addison-Wesley.

[19] House R J, Hanges P J, Javidan M, Dorfman P W and Gupta V GLOBE 2004 Leadership, culture and organizations: The GLOBE Study of 62 Societies. Thousand Oaks, CA: Sage Publications Inc. pp. 921-976.

[20] Zulfadrim Z, Toyoda Y and Kanegae H 2018 Indigenous knowledge in disaster risk reduction for natural disaster a case study from West Sumatera. IOP Conf. Ser.: Earth Environ. Sci., 106, 012008

[21] Park H A 2013 An introduction to logistic regression: From basic concepts to interpretation with particular attention to nursing domain. Journal of Korean Academy of Nursing, 43(2), 154-164. https://doi.org/10.4040/jkan.2013.43.2.154

[22] Tetrault J M, Sauler M, Wells C K and Concato J 2008 Reporting of multivariable methods in the medical literature. Journal of Investigative Medicine, 56(7), 954957. http://dx.doi.org/10.231/JIM.0b013e31818914f

[23] Pedhazur E J 1997 Multiple regression in behavioral research: Explanation and prediction (3rd ed.). New York, NY: Harcourt Brace.

[24] Ajzen I and Fishbein M 2010 Predicting and changing behavior: The reasoned action approach. New York, NY: Psychology Press. 